\title{
Ocorrência de Salmonella e Coliformes de Origem Fecal na Canela em Pó (Cinnamomum cassia Blume a Cinnamomum zeylanicum Nees) Comercializada em Florianópolis, Santa Catarina, Brasil
}

\author{
Salmonella and Fecal Coliforms in Cinnamon (Cinnamomum cassia Blume \\ and Cinnamomum zeylanicum Nees) Sold in the City of Florianópolis, \\ Santa Catarina, Brazil
}

Jane Maria de S. Philippi' \& Eliane Moretto²

PHILIPPI, J. M. S. \& MORETTO, E. Salmonella and Fecal Coliforms in Cinnamon (Cinnamomum cassia Blume and Cinnamomum zeylanieum Nees) Sold in the City of Florianópolis, Santa Catarina, Brazil. Cad. Saúde Públ., Rio de Janeiro, 11 (4): 624-628, Oct/Dec, 1995.

The microbiological quality of a hundred samples of ten differents commercial brands of a ground cinnamon (Cinnamomum cassia Blume and Cinnamomum zeylanicum Nees) from supermarkets in the city of Florianópolis, Brazil, was assessed. Salmonella and fecal coliforms were determined. Results were negative for Salmonella Fecal coliforms values ranged from <3 to 2,400 MPN per g. $63 \%$ of the samples showed values from <3 MPN per g; $34 \%$ showed values ranging front 3 to $100 \mathrm{MPN}$ per g, these being the legal acceptable values; $3 \%$ showed values $>100$ MPN per g. Fecal coliforms were detected in $37 \%$ of the cinnamon samples.

Key words: Cinnamon; Cinnamomum spp.; Salmonella sp.; Fecal Coliforms

\section{INTRODUÇÃO}

A canela em pó é o produto resultante da moagem da casca de Cinnamontum cassia Blume (canela-da-china) a de Cinnamomum zeylanicum Nees (canela-do-ceilão), sendo a ca-nela-da-China parcialmente privada do súber e a canela-do-Ceilão totalmente privada do súber a de uma parte do parênquima cortical externo. Pertencente à família Laureaceae, possui células secretoras com conteúdo oleoso (Farmacopéia Brasileira, 1977; MS, 1978). Contém de 1 a $2 \%$ de óleos essenciais, onde se comprovou a presença das seguintes substâncias: aldeído cinâmico (75-90\%), aldeído benzóico,

${ }^{1}$ Laboratório Central de Saúde Pública. Avenida Rio Branco, 197, Fundos, Florianópolis, SC, 88015-200, Brasil.

${ }^{2}$ Departamento de Ciência e Tecnologia de Alimentos, Centro de Ciências Agrárias, Universidade Federal de Santa Catarina. Rodovia SC 404, Km 3, Itacorubi. Florianópolis, SC, 88034-001, Brasil. ácido benzóico, éster do ácido cinâmico-cumarina, metil-orto-cumaraldeídó, éster metílico do ácido salicílico a ácido cinâmico (Gerhardt, 1973). As especiarias que contêm óleos essenciais de maior poder inibitório são o cravo, a pimenta-da-jamaica, a canela e a mostarda, sendo que na canela os componentes de maior efeito antimicrobiano são o aldeído cinâmico, o acetato cinâmico e o eugenol (ICMSF, 1985).

A maior parte das doenças infecciosas transmitidas pelos alimentos tem uma origem entérica, e por isso, um dos maiores perigos a que o consumidor está exposto é a contaminação por matérias fecais humanas ou animais (Ministério da Indústria e do Comércio, 1986). A Salmonella pode ocorrer em diversas especiarias, ainda que não seja freqüente (Leitão et al., 1974). De 0,7 a $20 \%$ de indivíduos podem ser portadores dessa bactéria e sua presença no alimento está vinculada ao manuseio anti-higiênico por portadores da mesma (Montes, 1977). 
Os coliformes de origem fecal desenvolvemse em matérias primas e alimentos obtidos de diferentes tecnologias, e não sendo constituintes da flora normal da maior parte deles, a sua presença pode ser utilizada como indicadora de contaminação indesejável (Ministério da Indústria e Comércio, 1986).

Em geral, os riscos sanitários que representa uma especiaria devem ser cuidadosamente avaliados em função do seu uso. A canela em pó requer matéria-prima de boa qualidade, assim como manipulação, embalagem e armazenamento adequados, para garantir sua pureza e suas características, assegurando sua inocuidade ao consumidor. $\mathrm{Na}$ maioria das vezes, a canela em pó é consumida sem, sofrer tratamento térmico. Pode assim contaminar o produto pronto, sem competidores bacterianos, que eventualmente já foram eliminados no preparo.

\section{MATERIAL E MÉTODOS}

A pesquisa foi realizada no Laboratório Central de Saúde Pública de Santa Catarina (LACEN/ $\mathrm{SC}$ ). As cem amostras foram coletadas em supermercados, escolhidas ao acaso como representativas do lote, e envolvendo todas as marcas comercializadas em Florianópolis. Na análise, as marcas foram codificadas em ordem alfabética de $\mathrm{A}$ a J, seguidas do número da amostra. Das dez marcas analisadas, oito eram de Santa Catarina e duas provenientes de São Paulo. Todas as marcas importavam o produto em casca da Indonésia e da Ásia.

Para isolamento e identificação de Salmonella, conforme bibliografia recomendada (Andrews et al., 1984; Peppler \& Guarino, 1984; Poelma et al., 1984; Mac Faddin, 1980), realizaram-se as seguintes etapas:

- Pré-enriquecimento: $25 \mathrm{~g}$ de amostra foram homogeneizadas com $225 \mathrm{ml}$ de água tamponada peptonada e incubada a $36^{\circ} \mathrm{C}$ por 16/18 horas em estufa bacteriológica.

- Enriquecimento: 1,0 $\mathrm{ml}$ do inóculo foi transferido para tubo de ensaio contendo $1 \mathrm{ml}$ de meio enriquecido à base de tetrationato segundo Muller-Kauffmann, adicionado de $0,1 \mathrm{ml}$ de solução de verde brilhante a $0,1 \%$ e $0,2 \mathrm{ml}$ de solução de iodeto de potássio; outra alíquota de 1,0 $\mathrm{ml}$ foi transferida para tubo de ensaio contendo $10 \mathrm{ml}$ de caldo de enriquecimento selenito-cistina. Foram incubados a $43^{\circ} \mathrm{C} \mathrm{em} \mathrm{BM}$.

- Isolamento: após 24 horas de incubação realizaram-se semeaduras em placas de Petri com meio seletivo para isolamento de Salmonella-Shigella (ágar SS) e com ágar lactose-sacarose-vermelho de fenolverde brilhante (ágar BG). Foram incubadas a $36^{\circ} \mathrm{C}$ por $24 / 48$ horas.

- Identificação bioquímica: colônias suspeitas no ágar SS e no ágar BG foram transferidas para tubos de ensaio contendo meio Instituto Adolfo Lutz (meio IAL), incubados a $36^{\circ} \mathrm{C}$ por 24 horas, fornecendo as provas bioquímicas.

- Confirmação sorológica: realizada com Salmonella polivalente flagelar-H e Salmonella polivalente somático-O.

Para a determinação do número mais provável de coliformes de origem fecal, segundo metodologia específica (Mehlman et al., 1984; Oblinger \& Koburger, 1984; Peppler \& Guarino, 1984) realizaram-se as seguintes etapas:

- Preparo da amostra: $25 \mathrm{~g}$ de amostra homogeneizados com $225 \mathrm{ml}$ de solução salina peptonada, fazendo-se diluições de $10^{-1}, 10^{-2}$ e $10^{-3}$.

- Teste presuntivo: $1 \mathrm{ml}$ de cada diluição foi transferido para tubos de ensaio contendo Bacto lauryl tryptose broth, com tubos de Duhran invertidos, incubados a $36^{\circ} \mathrm{C}$ por $24 / 48$ horas em estufa bacteriológica, fazendo-se uma série de três tubos para cada diluição.

- Teste confirmativo: dos tubos do teste presuntivo que apresentaram produção de gás, retiraram-se alíquotas com alça de platina, para tubos de ensaio contendo caldo Escherichia coli e tubos de Duhran invertidos, que foram incubados a $44,5^{\circ} \mathrm{C}$ em BM. 
Leitura dos resultados: os números de tubos com produção de gás foram comparados com a Tabela de NMP para diluições de $10^{-1}, 10^{-2}$ e $10^{-3}$ com três tubos por diluição.

\section{RESULTADOS}

Das cem amostras analisadas de canela em pó, todas apresentaram ausência de Salmonella em 25 gramas, satisfazendo a legislação em vigor (MS, 1987). Os valores de coliformes de origem fecal variaram de $<3$ a 2.400 $\mathrm{NMP} / \mathrm{g}$, sendo que a média geométrica variou de $<3$ a 17,42 NMP/g, conforme demonstrado na Tabela 1.

Sessenta e três por cento das amostras apresentaram valores de coliformes de origem fecal
$<3 \mathrm{NMP} / \mathrm{g} ; 34 \%$ apresentaram valores de 3 a 100 $\mathrm{NMP} / \mathrm{g} ; \mathrm{e} 3 \%$ apresentaram valores de 100 a 2.400 NMP/g, conforme demonstrado na Tabela 2.

TABELA 2. Incidência de Coliformes de Origem Fecal em 100 Amostras de Canela em Pó, de 10 Marcas Diferentes Comercializadas em Florianópolis, Santa Catarina

\begin{tabular}{lcc}
\hline \hline $\begin{array}{l}\text { Intervalo de } \\
\text { População (NMP/g) }\end{array}$ & $\begin{array}{c}\text { Número de } \\
\text { Amostras }\end{array}$ & $\%$ \\
\hline$<3$ & 63 & 63 \\
$3-10$ & 16 & 16 \\
$11-27$ & 10 & 10 \\
$28-100$ & 8 & 8 \\
$101-460$ & 2 & 2 \\
$461-2400$ & 1 & 1 \\
\hline Total de Amostras & 100 & 100 \\
\hline \hline
\end{tabular}

TABELA 1. Freqüência de Distribuição de Coliformes de Origem Fecal em 100 Amostras de Canela em Pó de 10 Marcas Diferentes, Comercializadas em Florianópolis, Santa Catarina

\begin{tabular}{|c|c|c|c|c|c|c|c|c|c|c|}
\hline \multirow{2}{*}{$\begin{array}{l}\text { Intervalo de } \\
\text { População } \\
(\mathrm{NMP} / \mathrm{g})\end{array}$} & \multicolumn{10}{|c|}{ Número de Amostras } \\
\hline & $\mathrm{A}$ & B & $\mathrm{C}$ & $\mathrm{D}$ & $\mathrm{E}$ & $\mathrm{F}$ & G & $\mathrm{H}$ & I & $\mathrm{J}$ \\
\hline$<3$ & 10 & 10 & 10 & 5 & 7 & 8 & 4 & 3 & 4 & 2 \\
\hline $3-10$ & 0 & 0 & 0 & 4 & 2 & 2 & 3 & 0 & 3 & 2 \\
\hline $11-27$ & 0 & 0 & 0 & 0 & 0 & 0 & 2 & 3 & 0 & 5 \\
\hline 28-Itb & 0 & 0 & 0 & 1 & 1 & 0 & 1 & 3 & 2 & 0 \\
\hline $101-460$ & 0 & 0 & 0 & 0 & 0 & 0 & 0 & 0 & 1 & 1 \\
\hline $461-2400$ & 0 & 0 & 0 & 0 & 0 & 0 & 0 & 1 & 0 & 0 \\
\hline \multicolumn{11}{|l|}{ Total de } \\
\hline Amostras & 10 & 10 & 10 & 10 & 10 & 10 & 10 & 10 & 10 & 10 \\
\hline Valores Limites & $<3$ & $<3$ & $<3$ & $<3-93$ & $<3-43$ & $<3-9$ & $<3-43$ & $<3-2400$ & $<3-150$ & $<3-150$ \\
\hline Média Geométrica & $<3$ & $<3$ & $<3$ & 3,20 & $<3$ & $<3$ & 4,79 & 17,42 & 7,08 & 11,14 \\
\hline
\end{tabular}

\section{DISCUSSÃO}

A presença de Salmonella em apenas uma amostra das dez analisadas de cada marca, tornaria esta marca imprópria para o consumo (MS, 1987), o que não ocorreu com nenhuma marca de canela em pó analisada.

Os coliformes de origem fecal são provenientes do manuseio inadequado no processa- mento do alimento, refletindo a sua qualidade higiênica (Banwart, 1989). Existe uma correlação entre a morbidade por gastroenterites e o nível de indicadores nos alimentos consumidos. Além disso, o seu uso para comprovar a qualidade do alimento é mais fácil, rápido, seguro e econômico do que a detecção de organismos patógenos (Ministério da Indústria e Comércio, 1986). O ideal seria que não fossem 
encontrados coliformes de origem fecal em nenhuma amostra (Jay, 1978), sendo que os dados apresentados são significativos para uma avaliação, pois $37 \%$ das amostras analisadas apresentaram coliformes de origem fecal.

\section{CONCLUSÃO}

Verificando os resultados obtidos, pode-se concluir:

- As amostras analisadas atendem as especificações da legislação em vigor do Ministério da Saúde, 1987, quanto à ausência de Salmonella.

- Quanto à presença de coliformes de origem fecal, 97\% das amostras apresentaram-se de acordo com os limites da legislação em vigor (MS, 1987), $2 \%$ apresentaram "condições higiênico-sanitárias insatisfatórias" e $1 \%$ "inaceitáveis para o consumo direto".

- Determinadas marcas analisadas demonstraram deficiências de um controle de qualidade industrial, podendo oferecer riscos para o consumidor.

\section{RESUMO}

PHILIPPI, J. M. S. \& MORETTO, E. Ocorrência de Salmonella e Coliformes de Origem Fecal na Canela em Pó (Cinnamomum cassia Blume e Cinnamomum zeylanicum Nees) Comercializada em Florianópolis, Santa Catarina, Brasil. Cad. Saúde Públ., Rio de Janeiro, 11 (4): 624-628, out/dez, 1995.

Cem amostras de canela em pó de dez marcas diferentes comercializadas na cidade de Florianópolis, SC, foram submetidas à análise microbiológica, pesquisando-se Salmonella e coliformes de origem fecal. Em nenhuma amostra foi detectada Salmonella. Coliformes de origem fecal foram encontrados entre os valores <3 a $2.400 \mathrm{NMP} / \mathrm{g}$. Das amostras analisadas, $63 \%$ apresentaram valores de <3 NMP/g; 34\% apresentaram valores entre 3 e $100 \mathrm{NMP} / \mathrm{g}$, limite este permitido pela legislação brasileira em vigor; e 3\% apresentaram valores superio- res a $100 \mathrm{NMP} / \mathrm{g}$. A presença de coliformes de origem fecal foi detectada em $37 \%$ das amostras de canela em pó.

Palavras-Chave:.Canela Cinnamomum spp.; Salmonella sp.; Coliformes Fecais.

\section{REFERÊNCIAS BIBLIOGRÁFICAS}

ANDREWS, W. H.; POELMA, P. L. \& WILSON, C. R., 1984. Isolation and identification of Salmonella species. In: Bacteriological Analytical Manual (Food and Drug Administration), 6o ed., pp. 7.01-7.17, Arlington: AOAC.

BANWART, G. J., 1989. Basic Food Microbiology. $2^{\mathrm{a}}$ ed, New York: An Avibook.

BRASIL. Decreto nº 78840 de 25.11.76. Farmacopéia Brasileira. $3^{\mathrm{a}}$ ed; São Paulo: Andrei.

GERHARDT, U., 1973. Especias y Condimentos. Zaragoza: Acribia.

ICMSF (International Commission on Microbiological Specifications for Foods), 1985. Ecología Microbiana de los Alimentos. II. Productos Alimenticios. Zaragoza: Acribia.

JAY, J. M., 1978. Microbiología Moderna de los Alimentos. 2' ed, Zaragoza: Acribia.

LEITAO, M. F. F.; DELASARI, I. \& MAZZONI, H., 1974. Microbiologia de alimentos desidratados. Coletânea do Instituto de Tecnologia de Alimentos, Campinas, 5: 223-241.

MAC FADDIN, J. F., 1980. Pruebas Bioquímicas para la Identificación de Bacterias de Importancia Clínica. Buenos Aires: Médica Panamericana.

MEHLMAN, I. J.; ANDREWS, W. H. \& WENTZ, B. A., 1984. Coliform bacteria. In: Bacteriological Analytical Manual (Food and Drug Administration), $6^{a}$ ed., pp. 501-507, Arlington: AOAC.

MINISTÉRIO DA INDÚSTRIA E COMÉRCIO, 1986. Microbiologia Aplicada às Industrias Alimentares. $2^{\mathrm{a}}$ ed., Lisboa: Instituto de Tecnologia e Indústria.

MONTES, A. L., 1977. Microbiología de los Alimentos. V. I. São Paulo: Resenha Universitária.

MS (Ministério da Saúde), 1978. Resolução nº 12178 da Comissão Nacional de Normas e Padrões para Alimentos. Aprova as normas técnicas especiais, do Estado de São Paulo, relativas a alimentos e bebidas. Diário Oficial da União, Brasília, 24 jul., Seção I, Parte I, p. 11521-5. 
1987. Portaria n⿳0 01/Dinal/MS de 28 de janeiro de 1987 da Divisão Nacional de Vigilância Sanitária de Alimentos. Aprova padrões microbiológicos. Diário Oficial da União, Brasília, 25 fev., Seção I, Parte I, p. 2197.

OBLINGER, J. L. \& KOBURGER, J. A., 1984. The most probable number technique. In: Compendium of Methods for the Microbiological Examination of Foods (American Public Health Association), $2^{\mathrm{a}}$ ed., pp. 99-111, Washington, DC: Marvil L. Speck.
PEPPLER, H. J. \& GUARINO, P. A., 1984. Spices and gums. In: Compendium of Methods for the Microbiological Examination of Foods (American Public Health Association), 2 ed., pp. 651-660, Washington, DC: Marvin L. Speck.

POELMA, P. L.; ANDREWS, W. H. \& SILLIKER, J. H., 1984. Salmonella. In: Compendium of Methods for the Microbiological Examination of Foods (American Public Health Association), 2e․, pp. 286-320, Washington, DC: Marvin L. Speck. 